\title{
RECONHECIMENTO NA VIDA DANIFICADA: HONNETH LEITOR DE ADORNO
}

\section{CARLOS CÉSAR BARROS ${ }^{1}$}

RESUMO: Este artigo se propõe ao estudo do diálogo estabelecido pela teoria do reconhecimento de Axel Honneth com o pensamento de Theodor Adorno. Mais precisamente, dirige seu foco para a proposição de que já haveria em Adorno elementos teóricos que ajudam a compreender o fenômeno da reificação numa perspectiva do reconhecimento. Num primeiro momento, apresenta uma síntese das diferentes leituras que Honneth fez de Adorno num intervalo de aproximadamente trinta anos. Depois, analisa alguns dos principais temas expressos em aforismos adornianos, aos quais Honneth se refere no desenvolvimento de seus argumentos. Duas teses emergem como uma aproximação possível entre os dois autores. A primeira afirma um referencial normativo na infância e na família, baseado na mimese e na intersubjetividade enquanto processos vinculados às noções de experiência, gramática gestual, espontaneidade, ludicidade e utopia. A segunda, derivada do referencial normativo, afirma a patologia social como deperecimento da experiência, danificação da vida, deformação da racionalidade mimética, reificação e sofrimento, sem, no entanto, deixar de encontrar nessas categorias um potencial de resistência. Por fim, o texto menciona algumas críticas à tentativa honnethiana de aproximação com Adorno e destaca a tendência de reconstrução da teoria crítica com base na filosofia da linguagem.

PALAVRAS-CHAVE: reconhecimento; Axel Honneth; Theodor Adorno.

ABSTRACT: This paper proposes to study the dialogue established by the theory of recognition of Axel Honneth with the thinking of Theodor Adorno. More precisely, it directs its focus to the proposition that there would already be in Adorno theoretical elements that help to understand the phenomenon of reification in a perspective of recognition. At first, it presents a synthesis of the different readings that Honneth made of Adorno in an interval of approximately thirty years. It then analyzes some of the major themes expressed in Adornian aphorisms, to which Honneth refers in the development of his arguments. Two theses emerge as a possible approximation between the two authors. The first affirms a normative reference in childhood and in the family, based on mimesis and intersubjectivity as processes linked to 
the notions of experience, gestural grammar, spontaneity, playfulness and utopia. The second, derived from the normative referential, affirms the social pathology as depletion of experience, damage of life, deformation of mimetic rationality, reification and suffering, without, however, failing to find in these categories a potential for resistance. Finally, the text mentions some criticisms to the Honnethian attempt of approach with Adorno and emphasizes the tendency of reconstruction of the critical theory based on the philosophy of the language.

KEYWORDS: Recognition; Axel Honneth; Theodor Adorno.

Um tema possível no contexto dos conflitos geracionais da Escola de Frankfurt surge do confronto entre o suposto otimismo de Axel Honneth, representante da terceira geração, e o suposto pessimismo paralisante de Adorno, destacado nome da primeira geração. $\mathrm{O}$ conceito que sintetiza o posicionamento teórico de Honneth é o de "reconhecimento", termo mais importante de sua tese de livre-docência (Honneth, 2003 [1992]), na qual propôs uma teoria que pudesse superar tanto a primeira quanto a segunda geração, representada por Habermas, já criticadas em sua tese de doutorado (Honneth, 2009 [1988]). Quando Adorno elaborou algumas de suas mais inspiradas análises sociais, nos anos quarenta, denominou-as "reflexões a partir da vida danificada" (Adorno, 1993 [1951]). O principal objetivo deste trabalho é reunir elementos que possam lançar alguma luz sobre a questão do reconhecimento na vida danificada, oferecendo uma imagem da atualidade e das potencialidades da teoria crítica.

Dada a amplitude do tema, vamos começar com uma sistematização das leituras que Honneth faz de Adorno, dispersas num intervalo de cerca de trinta anos. De início, Adorno é caracterizado como o principal agente da instauração do "déficit sociológico", da repressão do social na teoria crítica. Mais tarde, sua dialética negativa será incorporada em argumentos complexos da teoria do reconhecimento. Depois dessa condensação de diversos textos, procuraremos nos aforismos adornianos, destacados por Honneth em seus artigos, elementos que justifiquem a proposta de reconciliação. A hipótese que sustenta tal projeto reconciliatório é a de que já existiriam elementos de teoria do reconhecimento no autor da dialética negativa, corroborando seu compromisso normativo com o projeto original da teoria crítica.

Em nossas considerações finais, daremos algum espaço para as críticas ao projeto de Honneth e a configuração de um fértil campo de pesquisa que envolve reconhecimento, 
filosofia da linguagem e psicologia/psicanálise. A teoria do reconhecimento tem sido desenvolvida com os métodos da atualização e da reconstrução (Honneth, 2009 [2000]; Nobre; Repa, 2012). O caso exemplar é a filosofia de Hegel - do período de Jena (Honneth, 2003 [1992]) ou do direito (Honneth, 2007 [2001c]) -, reconstruída a partir da filosofia e da sociologia da ação, da virada linguística e da psicanálise das relações objetais. De certa forma, Honneth se dedicou a um exercício semelhante com o pensamento de Adorno, como veremos adiante em passagens que mencionam possíveis aproximações com Dewey, Wittgenstein, Putnam ou Cavell. Parece ser um caminho que se apresenta como atualidade e potência da teoria crítica, quando estudos que partem diretamente do pensamento de Adorno, sem maiores menções a Honneth, apontam para a mesma direção (Foster, 2007; Hogh, 2016).

\section{Honneth leitor de Adorno}

As diferentes leituras de Adorno feitas por Honneth, do final dos anos setenta até a primeira década deste século, apresentam uma estrutura que passa por uma fase ambivalente, um período de latência e, por fim, a constatação de que a teoria adorniana poderia ser incorporada à teoria do reconhecimento. No contexto dos anos iniciais de sua produção, Honneth tomou o partido da então em construção teoria da ação comunicativa de Habermas, que foi desenvolvida em confronto direto com o influente pensamento do recém-falecido Adorno (Honneth, 1995 [1979]). Afirmou sua filiação ao projeto inicial da teoria crítica, elaborado por Horkheimer nos anos trinta, em sua tese de doutorado de 1985, que se tornou, em versão ampliada, o livro Crítica do poder (Honneth, 2009 [1988]). O potencial de análise social da atitude crítica pré-teórica, que Horkheimer traduziu como historicidade e normatividade na teoria crítica, poderia ter sido desenvolvido a partir de seu conceito de cultura. Porém, a influência prejudicial da crítica cultural e da filosofia da história de Adorno teria sido responsável pela "repressão definitiva do social" na teoria crítica. Honneth chegou a buscar em Foucault e Habermas um remédio para o déficit sociológico instaurado. Foi nessa busca, todavia, que percebeu um lado bom na teoria adorniana: um potencial crítico baseado na psicologia, numa concepção de subjetividade que interpretava o sofrimento como possibilidade de resistência fora do campo da linguagem e da racionalidade instrumental. Enfim, era possível identificar em Adorno um aspecto da normatividade inerente ao procedimento crítico frankfurtiano original (Honneth, 1995 [1986]). Veio, então, o período de latência, por cerca de uma década. Num período que vai de 1998 a 2007, ainda com algumas críticas, passou a predominar o respeito pelo caminho e pelo estilo da crítica social adorniana, 
agora reconhecida como uma hermenêutica materialista que abarca diversos elementos normativos passíveis de serem incorporados à teoria do reconhecimento.

A influência das inovações epistemológicas de Habermas na teoria crítica ressoa nas duas principais críticas que Honneth dirigia a Adorno: sua filosofia da história reduz o complexo de ações sociais à ação instrumental; sua filosofia da consciência é obsoleta diante da virada pragmática e intersubjetiva. Quando todo o processo histórico da racionalidade pode ser explicado por uma redução à relação de dominação humana sobre a natureza, a teoria crítica se concentra na descrição de um processo filogenético da desintegração social, deixando uma significativa lacuna no que diz respeito à interação (Honneth, 1999 [1989]). As principais teses da Dialética do Esclarecimento - obra em que Horkheimer e Adorno levaram a cabo tal filogênese - estariam baseadas na reducionista antropologia filosófica de Alfred Sohn-Rettel, recaindo em uma antropogênese regressiva e funcionalista (Honneth, 2009 [1988]). Defensor de uma teoria complexa da ação social - fundamentada numa antropologia filosófica construída a partir de autores como Arnold Gehlen, Helmut Plessner, Agnes Heller e, principalmente, George Mead (Honneth; Joas, 1988 [1980]) -, Honneth considerava a teoria adorniana do Eu demasiado esquemática por se fundamentar em uma inaceitável teoria dos impulsos, partindo do pressuposto da relação reificadora do homem com a natureza sem qualquer intersubjetividade. O excurso sobre Odisseu na Dialética do Esclarecimento constrói uma relação direta entre dominação da natureza e controle das pulsões: "na Dialética do Iluminismo [Outro modo de falar na Dialética do Esclarecimento], Horkheimer e Adorno são forçados a conceber toda ação social segundo o mesmo padrão de arsenal instrumental de um sujeito sobre um objeto". (Honneth, 1999 [1989], p. 52).

É plausível que a partir de suas diferenças para com Habermas, concentradas nas expressões ocultas da moralidade em formas de resistência não discursivas (Honneth, 1995 [1981]), Honneth tenha visto com bons olhos as reflexões de Adorno sobre a mimese e o corpo. Ainda que não tenha enfatizado essa abordagem, encontra-se na Crítica do Poder (Honneth, 2009 [1988]) uma leitura da mimese como origem da racionalidade, expressandose coletivamente na magia antes de sua reificação nos desdobramentos do esclarecimento em mito, filosofia e ciência. É provável que aqui encontremos a semente do que mais tarde germinará como uma abordagem intersubjetivista da mimese enquanto condição da racionalidade ou, em outras palavras, do reconhecimento como anterior ao conhecimento (Honneth, 2008). O tema do corpo se destaca na abordagem da semelhança entre Foucault e 
Adorno quando descrevem a violenta escravização e mutilação do corpo, seja na história europeia subterrânea, para Horkheimer e Adorno, seja na disciplina cotidiana para Foucault. No entanto, há "uma pequena diferença que, de fato, fará toda diferença" (Honneth, 1995 [1986], p. 128): o conceito de sujeito subjacente às suas análises sociais. A influência estruturalista teria conduzido Foucault a uma psicologia quase behaviorista, entendendo os indivíduos como sem forma e condicionáveis. Já Adorno viu na dominação um obstáculo à autodeterminação dos indivíduos. O que em Foucault é ontológico, em Adorno é um produto histórico do processo civilizatório: "ele tem algo mais em mente com sua problematização da individualidade moderna, que Foucault com sua ideia de uma desconstrução do sujeito" (Honneth, 1995 [1986], p. 129). Adorno ainda pensa a possibilidade de um corpo livre, vendo no sofrimento psíquico uma expressão não linguística do impulso para a reconciliação entre corpo e civilização. Apesar de sua problemática filosofia da história, Adorno ainda manteve a possibilidade de atacar criticamente os processos objetivos de poder com uma normatividade baseada na mimese e no corpo.

A partir do final dos anos noventa, Honneth se debruça sobre diferentes possíveis leituras da forma e do conteúdo dos escritos adornianos para renovar suas interpretações. Aos que leem Adorno apenas como um arauto do Apocalipse ou como um poeta, Honneth adverte que ele fez mais que crítica da cultura ou ficção. Deve ser levado a sério como um filósofo da normatividade em suas denúncias das patologias sociais (Honneth, 2011 [1998]). Aos que veem na teoria adorniana uma atitude explicativa deficitária, como o jovem Honneth, parece mais sensato considerá-la como uma hermenêutica materialista com elaborados recursos retóricos $^{2}$ (Honneth, 2009 [2006b]; 2009 [2005]). Agora a Dialética do Esclarecimento aparece como uma solução para o dilema das patologias sociais em torno da autonomia individual e do pluralismo axiológico:

\begin{abstract}
Minha tese é que a Dialética do Iluminismo representa uma solução adequada e convincente para esse dilema, porque leva a cabo um diagnóstico da patologia na forma de uma crítica esclarecedora do mundo: pela renúncia a pressupostos metafísicos, o juízo normativo não foi justificado racionalmente, mas apenas invocado intencionalmente no leitor, oferecendo a ele uma nova descrição tão radical das condições da vida social que tudo deve adotar subitamente o novo significado de uma situação patológica. (Honneth, 2011 [1998], p. 158).
\end{abstract}

Dentre os dois caminhos possíveis para o propósito crítico, Adorno renunciou ao positivo, da boa vida alternativa, pelo negativo, da denúncia da vida falsa. Os efeitos patológicos da racionalidade técnica sobre nossas relações sociais são abordados não pela fundamentação argumentativa, mas por um estilo retórico - composto por narrativas, 
metáforas, quiasmas, exageros, condensações e deslocamentos de significados - que possibilita a emergência de fatos ainda não percebidos. Sua denúncia das patologias sociais considera, tal como o pragmatismo de Hilary Putnam - para mencionar a reconstrução pragmática de Honneth -, uma dependência mútua entre convicções axiológicas e realidade (Honneth, 2011 [1998]). Aprofundando-se na "hermenêutica materialista da história natural" adorniana, Honneth (2009 [2005]) revisita textos iniciais e programáticos de Adorno, a fim de encontrar as origens de sua concepção de mimese e do método fisiognômico, desenvolvidos sob as influências de Walter Benjamin, Georg Lukács e Max Weber. Os debates sobre naturalização de relações históricas, reificação e tipos ideais demonstram que, da assimilação crítica desses autores, emerge, em primeiro lugar, uma teoria da mimese vinculada ao cuidado amoroso, que dá origem à racionalidade não reificada. Depois, o desenvolvimento do conceito de fisiognomia e da arte do exagero, vinculados aos tipos ideais ${ }^{3}$, buscando formar uma figura hermenêutica das patologias sociais com destaque para a expressão corporal, daí o termo fisiognomia (Honneth, 2009 [2005]). A denúncia dos fatos que impossibilitam ou levam à regressão da "razão mimética" também evidencia que eles geram formações reativas passíveis de interpretação na comunicação gestual. De sua leitura da Dialética Negativa, Honneth destaca, no método adorniano, os elementos que escapam à "racionalidade positivista" (termo usado em sentido amplo o suficiente para abarcar a própria dialética). A experiência filosófica só é possível se levamos em conta a genealogia, não apenas em termos históricos ou filológicos, mas no que ela revela do negativo da razão: é preciso "trazer também à luz as raízes pré-intelectuais, pulsionais ou práticas de todos os fenômenos intelectuais" (Honneth, 2009 [2006b], p. 92). Se Nietzsche e Freud abriram os caminhos para a compreensão do préintelectual como a base irrefletida dos conceitos, Adorno supera seus mestres apontando para uma nova liberdade intelectual na experiência subjetiva, com um incremento de diferenciação e sensibilidade. O projeto filosófico de Adorno, de reconciliar os fragmentos com o objeto que sofreu a violência conceitual, revela-se, agora, herdeiro da antropologia expressivista ${ }^{4}$ anteriormente utilizada para denunciar seu déficit sociológico.

Encerrada nossa breve exposição sobre a forma ou estilo, podemos afirmar, com ênfase no conteúdo - ainda que seja herético separá-los quando falamos de Adorno -, que duas teses centrais de Honneth sobre a teoria do reconhecimento foram desenvolvidas em diálogo direto com a teoria adorniana. A primeira delas é a de que o reconhecimento precede o conhecimento ${ }^{5}$. Em um ensaio sobre a invisibilidade social, que trata do preconceito, Honneth (2011 [2001b]) retoma as relações entre corpo, antropologia expressivista, segunda 
natureza e reconhecimento. Sua "epistemologia moral" do reconhecimento afirma que este abarca muito mais que expressões linguísticas, tem um aspecto performático e gestual que se torna figura sobre o fundo de uma segunda natureza, descrita como "gramática da comunicação gestual". Tal natureza tem, no corpo e em suas expressões, elementos centrais da interação que define as ações de reconhecimento. O material empírico para corroborar sua tese foi encontrado nas pesquisas de Helmut Plessner, sobre formas de expressão da ação moral, e de René Spitz e Daniel Stern, que "puderam mostrar que o desenvolvimento socializador nos primeiros anos de vida se efetua na forma de um processo de regulação recíproca dos afetos e atenções, que se leva a cabo, de maneira considerável, com ajuda do meio de uma comunicação gestual" (Honneth, 2011 [2001b], p. 171). Esse meio é composto pelo repertório de expressões gestuais e mímicas na interação com "espelhos expressivos", ou seja, com as pessoas que cuidam do bebê e interagem na elaboração de expressões faciais, esquema corporal e movimentos expressivos que formam o aspecto performático do reconhecimento. Gestos pré-linguísticos, como o sorriso e a compaixão, são exemplos dos processos de reconhecimento que começam na infância, numa abertura para o mundo dos valores, e que permanecem na vida adulta.

\begin{abstract}
A situação do reconhecimento é, como vimos até agora, a manifestação expressiva do fato de um indivíduo ficar descentrado, que efetuamos levando em conta o valor de uma pessoa: mediante os gestos e os comportamentos correspondentes, damos a conhecer publicamente que concedemos a outra pessoa, sobre a base de seu valor, uma autoridade moral sobre nós, na qual encontra limite a realização de nossos impulsos e inclinações espontâneas. Assim que compreendemos que essa experiência do valor de uma pessoa possui a forma de uma percepção, que começa com o sorriso reativo da criança pequena, a mera identificação cognitiva de um ser humano parece perder sua aparente supremacia natural sobre o reconhecimento; o reconhecimento precede o conhecimento ao menos geneticamente, na medida em que o lactante deduz das expressões faciais, em primeiro lugar, as características valiosas das pessoas, antes que esteja na posição de fazer uma consideração desinteressada de seu entorno. E o que é válido para a criança pequena não perdeu nada de seu significado fundamental no adulto: normalmente, também no marco da interação social com os outros, percebemos em primeiro lugar as características valiosas de uma pessoa inteligível, enquanto a mera identificação cognitiva de um ser humano representa um caso especial da neutralização de um processo original de reconhecimento (Honneth, 2011[2001b], p 180).
\end{abstract}

O descentramento de um indivíduo, pré-requisito do conhecimento enquanto percepção do mundo objetivo, é antes de tudo um processo intersubjetivo. Os experimentos e observações de Stern (2002) e Spitz (2013), tal como as teorias de Mead (1967) e Winnicott (1975), evidenciam todo um aspecto relacional que precede as relações do bebê com objetos não subjetivos. Chegamos, com isso, à elaboração mais recente de Honneth (2008) de que o reconhecimento, enquanto interação e intersubjetividade, tem prioridade ontogenética sobre o 
conhecimento ou as relações objetivas: "o comportamento humano se distingue pela posição comunicativa alcançada por meio da tomada de perspectiva de uma segunda pessoa" (Honneth, 2008, p. 41). Ao destacar que apenas com segurança afetiva as crianças podem entrar no mundo simbólico e da linguagem, Honneth (2008) encontra suporte em autores como Tomasello (1999; 2014), Hobson (2002) e, principalmente, Adorno (1993 [1951]). Para o frankfurtiano, a mente se origina da imitação de uma pessoa amada, e esta herança mimética pode ser uma pista para a normatividade da teoria crítica.

\begin{abstract}
O que não deseja ressequir [...] se alimenta da herança mimética. O que é humano está preso à imitação: um ser humano só se torna um ser humano na medida em que imita outros seres humanos. É nesse comportamento, a forma primitiva do amor ${ }^{6}$, que os sacerdotes da autenticidade farejam pistas daquela utopia capaz de abalar a estrutura da dominação. (Adorno, 1993 [1951], p. 136).
\end{abstract}

Tal simpatia afetiva em relação a outras pessoas é o que possibilita às crianças, pela primeira vez, experimentar suas perspectivas no mundo como tendo um significado (Honneth, 2008). A cathexis libidinal é o combustível desse processo. Mais que isso, "Adorno sustenta que a precisão de nosso conhecimento depende da extensão de reconhecimento emocional ou aceitação afetiva do maior número de perspectivas possível” (Honneth, 2008, p. 46). Também atribui à imitação primordial a possibilidade de uma boa relação da humanidade com a natureza, mediada pela mimese das figuras de amor, que podem favorecer formas de reconhecimento dos entes não humanos. "Nosso reconhecimento da individualidade de outras pessoas demanda que percebamos objetos na particularidade de todos aqueles aspectos que eles vinculam a esses objetos em suas respectivas visões destes" (Honneth, 2008, p. 62). Em ressonância com a doutrina da semelhança de Walter Benjamin, vale a pena lembrar que a mimese não se dá apenas com pessoas, mas também com objetos como trens e moinhos de vento (Benjamin, 1994). A partir da teoria do conhecimento de Adorno, considerando sua genealogia negativa, Honneth também estabelece possíveis relações com autores como JeanPaul Sartre, Stanley Cavell e Ludwig Wittgenstein para concluir que "o reconhecimento do outro constitui um pré-requisito não epistêmico para a compreensão linguística" (Honneth, 2008, p. 50). Em suma, a intersubjetividade e a afetividade, como descritores do reconhecimento, não apenas estão na origem do conhecimento, como são condições para um conhecimento preciso que, em oposição à racionalidade instrumental reificadora, é capaz de uma relação conciliadora com a diferença, os objetos e a natureza.

A segunda tese central, extraída do aforismo Le prix du progrès, é a de que "toda reificação é um esquecimento" (Horkheimer; Adorno, 1985, p. 215). Em uma analogia aos 
relatos do fisiologista Pierre Flourens sobre o clorofórmio - nos quais afirma que este não seria uma anestesia verdadeira, mas faria apenas com que a pessoa esquecesse a extrema dor sofrida -, Adorno e Horkheimer sugerem que nossa cegueira para o sofrimento é como o esquecimento por clorofórmio, com severas consequências inconscientes. Uma delas, exposta como crítica da ciência enquanto racionalidade reificadora, é "a perda da lembrança como condição transcendental da ciência" (Horkheimer; Adorno, 1985, p. 215). É, portanto, no esquecimento da aceitação afetiva, que garantiria a precisão do conhecimento, que se constitui o a priori da ciência objetivista condenada à recaída no mito. É nesse contexto argumentativo que se chega à conclusão de que a reificação é um esquecimento do reconhecimento (Honneth, 2008). Haveria nessa afirmação ampla, no entanto, uma imprecisão. Existem diferentes tipos de esquecimento do reconhecimento, e um deles não merece ser chamado de reificação. Talvez fosse mais preciso afirmarmos que há um processo contínuo de "objetificação", comum na passagem do reconhecimento de pessoas para o conhecimento de coisas. Em defesa dessa diferenciação, Honneth recorre a Martin Heidegger, John Dewey e Stanley Cavell, mas

\footnotetext{
Adorno enfatizou mais que qualquer outro escritor o fato de que a adequação e a qualidade de nosso pensamento conceitual é dependente do grau em que somos capazes de manter consciência da conexão original de nosso pensamento com um objeto de desejo - uma pessoa ou coisa amada. Ele ainda considera a memória desse antecedente ato de reconhecimento como provendo um tipo de garantia de que uma dada ação de cognição não construiu seu objeto, mas o alcançou em toda sua particularidade concreta (Honneth, 2008, p. 57).
}

Nenhum dos autores mencionados opõe o pensamento conceitual ao seu pré-requisito não epistêmico e empático. Estão convencidos, pelo contrário, de que quando os esforços reflexivos perdem consciência do antecedente de reconhecimento é que cruzamos a fronteira da patologia da razão, do ceticismo ou, nos termos de Adorno, do pensamento da identidade.

\section{Reconhecimento na vida danificada}

As reflexões adornianas a partir da vida danificada, sob a perspectiva honnethiana, podem ser interpretadas como um diagnóstico agudo das patologias sociais. O elemento normativo, inerente à teoria crítica, recebeu uma nova luz no palco da teoria do reconhecimento quando esta atentou para o fato de que algo se torna danificado, distorcido, o que pressupõe um critério normativo: a vida. As contradições inerentes à barbárie contemporânea ganharam expressão em "quiasmas retóricos" como "a vida não vive" ou "saúde para a morte" (Adorno, 1993 [1951]). A vida permanece, ainda que danificada. A incompatibilidade entre as filosofias da consciência e da história, atribuídas à primeira 
geração da teoria crítica, e com a virada comunicativa, da segunda geração, parece ter motivado o esforço de Honneth em abordar a filosofia de Adorno a partir de tendências filosóficas mais recentes. Suas críticas à teoria da ação comunicativa e sua opção pela antropologia expressivista encontraram um caminho fértil no pensamento adorniano.

O conceito de mimese, lido como intersubjetivo, torna-se central nesses esforços teóricos. Ele acompanha a filogênese e a ontogênese da vida racional não deformada. Da hipótese de que a magia era uma expressão da mimese chegamos a uma nova abordagem: o cuidado amoroso passa a ser a caracterização principal da mimese intersubjetiva. A genealogia da racionalidade precisa levar em conta seu pré-requisito afetivo e todo um complexo comunicativo da gramática gestual. Esse aspecto da vida pode se tornar espontaneidade, utopia, resistência, ou, pelo sofrimento, recair no processo de deformação da racionalidade e de reificação. Ainda assim, é possível identificar no sofrimento a vida que quer viver, o corpo que resiste.

A revisão dos argumentos de Adorno por Honneth acabou se estendendo a uma revisão de Freud. O quase sempre criticado criador da psicanálise, por seus pressupostos controversos, passou a ser lido como um autor que expressava a apropriação da liberdade na relação do indivíduo consigo mesmo (Honneth, 2009 [2006a]). O sofrimento é uma categoria de destaque:

Minha convicção é que Adorno enriquece seu conceito de "sofrimento" dotando-o [...] de componentes que provêm da psicanálise freudiana: o sofrimento, enquanto impulso com o qual os sujeitos reagem à condição de vida capitalista se converte [...] no desejo pré-reflexivo de libertar-se de condições que travam nosso potencial de razão mimética. (Honneth, 2009 [2005], p. 83).

Por um lado, as reações de sofrimento têm um representante na consciência que inclui a percepção da limitação da razão. Tal impulso, por si só, indica uma motivação para a mudança. Por outro, a sensação de dor contém o desejo de libertação desta, tal como o sofrimento neurótico motiva a necessidade da cura. "Transferindo ao sistema da crítica do capitalismo [...], os impulsos de sofrimento garantem, dito de maneira extrema, uma capacidade de resistência dos sujeitos às exigências instrumentais da forma de vida capitalista" (Honneth, 2009 [2005], p. 84).

A partir de agora, abordaremos os temas da vida, do potencial normativo do cuidado amoroso e do sofrimento enquanto resistência. O caminho será a interpretação e exposição de algumas das principais ideias encontradas na leitura dos aforismos da Minima Moralia 
(Adorno, 1993[1951]) aos quais Honneth recorreu em sua argumentação: Banquinho sobre a relva (2); Asilo para desabrigados (18); Não bater à porta (19); Segunda colheita (72); Intellectus sacrificium intellectus (79); A prova do ouro (99); Lojinha de brinquedo (146); Novissimum Organum (147).

\section{Genealogia afetiva da racionalidade: mimese e intersubjetividade}

Em Adorno, a gênese da racionalidade só pode ser compreendida em conjunto com a gênese da moralidade, a partir de sentimentos positivos e negativos. Ele mesmo recorre a Nietzsche para afirmar a relação diretamente proporcional entre sexualidade e produção cultural. Se entendemos a sexualidade no sentido amplo freudiano, podemos afirmar que a tese central da genealogia da racionalidade é que os impulsos são a base sobre a qual se constitui a racionalidade. A memória é fruto do amor; a criatividade ou a transformação resultam da fantasia; a percepção emerge do desejo ou do medo:

\footnotetext{
Não é a memória inseparável do amor, que pretende conservar o que passa? Não é cada impulso da fantasia engendrado pelo desejo, que, deslocando os elementos do existente, transcende-os sem traí-los? A mais simples das percepções não se forma no medo da coisa percebida ou no desejo desta última? (Adorno, 1993 [1951], p. 106-7).
}

A falsa ilusão do conhecimento que se pretende objetivo, ao afastar-se dos afetos, é denunciada como o intelecto que sacrifica a si mesmo. O conhecimento do objeto implica necessariamente o reconhecimento da subjetividade inerente ao conhecer. $\mathrm{O}$ próprio ato básico da percepção já é subjetivo. Em sua complexidade, contém a interação entre as diversas faculdades do conhecimento: "as faculdades, elas mesmas desenvolvidas através da interação, atrofiam-se quando são dissociadas umas das outras" (Adorno, 1993 [1951], p. 79). Adorno, no entanto, não faz uma defesa do irracionalismo, entregando o conhecimento ao mundo puro das emoções. Também dirige sua crítica, como temos visto, à objetividade repressora dos afetos. Sua proposta é a superação (Aufhebung), enquanto transformação que preserva, dos impulsos e afetos em uma plena experiência do conhecer.

"O pensamento que mata o desejo, seu pai, se vê surpreendido pela vingança da estupidez" (Adorno, 1993 [1951], p. 107). Essa engenhosa referência ao Édipo Rei, na qual o desejo é Laio e o pensamento, Édipo, descreve o destino da cegueira reificante da razão. Lançando mão da terminologia kantiana, que descreve a estética como o campo das sensações e percepções, Adorno afirma que a consciência que desconfia da memória acaba por perder sua dimensão histórica e imaginativa, afetando a apercepção sintética, faculdade da relação 
entre o $\mathrm{Eu}$ e as representações, à qual é inerente a reprodução na imaginação como rememoração. Com o exílio da fantasia, a possibilidade de estabelecer relações fica desterrada, vivendo como estrangeira no inconsciente e acusada de infantilismo: "apenas a fantasia, hoje consignada ao domínio do inconsciente e no conhecimento como um rudimento infantil e sem juízo, institui aquela relação entre objetos que é a fonte irrevogável de todo juízo: se ela é banida, então o juízo - o ato de conhecimento propriamente dito - também se vê exorcizado" (Adorno, 1993 [1951], p. 107). Sem a relação afetiva com as coisas, o conhecimento se torna impossível: "uma vez suprimido o último traço de emoção, o que resta do pensamento é apenas a absoluta tautologia" (Adorno, 1993 [1951], p. 107). Trata-se de uma castração da própria percepção e da razão, num ato edípico de furar os próprios olhos ao recusar toda antecipação desejante, repetindo de forma impotente o que já é conhecido.

Outra lição que o pai do pensamento, o desejo, tem a nos ensinar é a de que o nosso narcisismo, enquanto busca do puro e autêntico, está fadada ao fracasso. Agora Adorno se apoia nos antípodas Hegel e Schopenhauer para afirmar que o Eu é uma abstração: "apenas o resultado de uma separação social do processo social". Sempre há algo, desde as primeiras experiências infantis, "de imitação, de jogo, de vontade de ser diferente" (Adorno, 1993 [1951], p. 135). Como vimos anteriormente, o arquétipo do amor e do desejo está baseado no comportamento e na herança provenientes da mimese, o que nos faz humanos é a imitação de outros humanos. A gênese da racionalidade foi encontrada nas experiências afetivas que, por sua vez, tomam forma nas relações intersubjetivas de imitação.

\section{A infância e o lúdico como normatividade}

De uma forma geral, a crítica da vida danificada precisa ter um referencial do que seria a vida enquanto tal. Para compreender uma patologia social, é preciso ter alguma ideia do que seria uma condição social não patológica. Se a normatividade da teoria crítica precisa ser referenciada historicamente e empiricamente, um caminho possível, proposto por Hegel e atualizado por Honneth (2003 [1992]), é o estudo da família e da infância. Com toda a crítica que dirige à instituição familiar, Adorno (1993 [1951], p. 17) reconhece que

tudo leva a crer que a malfadada célula da sociedade, a família, seria também a célula protetora da intransigente vontade de uma outra sociedade. Com a família desfez-se, enquanto o sistema subsiste, não somente a mais eficaz instituição burguesa, mas a resistência, que decerto reprimia o indivíduo, mas também o reforçava, se é que não o produzia pura e simplesmente. O fim da família paralisa as forças de oposição. A ordem coletivista nascente é um escárnio para com os semclasse: com o burguês liquida-se ao mesmo tempo a utopia que outrora se nutria do amor da mãe. 
A resistência, as forças de oposição, a intransigente vontade de uma outra sociedade e a utopia se alimentam do amor materno, da segurança familiar. A felicidade é "uma cópia da segurança dentro da mãe" e a base da dignidade (Adorno, 1993 [1951], p. 97). O contexto de segurança é o que possibilita a magia, a espontaneidade e a multiplicidade como elementos da experiência infantil. A perda dessa condição no mundo administrado faz regredir os elementos da experiência. Em "Lojinha de brinquedo", Adorno acompanha uma reflexão do diário de Hebbel sobre a perda da magia da infância, que nos traz à memória a condição filogenética e ontogenética da magia como condição da razão. As crianças se encantam com os saltimbancos por pensar que tudo acontece por alegria e gosto no que se faz, já os adultos sabem que eles fazem aquilo para pagar suas contas. Mas o que mudou da criança para o adulto? Ao contrário da resposta fácil de que a realidade virá a se impor sobre o infantilismo, numa espécie de desencantamento do mundo infantil, Adorno (1993 [1951], p. 200) advoga que as crianças não têm uma visão ilusória do mundo: "a percepção espontânea ainda apreende a contradição entre o fenômeno e a fungibilidade - que a percepção resignada dos adultos não alcança mais - e tenta a ela se subtrair. O jogo é a defesa delas". Na resignação adulta, a encantadora multiplicidade do mundo se torna pura monotonia: "nossos órgãos não captam o sensível isoladamente, mas reparam se a cor, se o som, se o movimento é para si ou para uma outra coisa". Nossa percepção não se dá fora do contexto dos valores que a acompanham. "O desencantamento do mundo sensível é a reação do sensorium à determinação objetiva desse mundo como 'mundo de mercadorias"' (Adorno, 1993 [1951], p. 199). Na sociedade do valor de troca, a incorruptibilidade da criança faz saltar aos olhos o valor de uso ${ }^{7}$.

O brincar pode ser caracterizado, aqui, como a forma defensiva de lidar com a transitoriedade do fenômeno. Mas essa defesa de forma alguma deve ser compreendida como patológica. Ao contrário, ela faz do brincar a negação do mundo dado e o princípio da justiça. "A irrealidade dos jogos anuncia que o real ainda não o é. Eles são exercícios inconscientes para a vida justa" (Adorno, 1993 [1951], p. 200). Uma das raras construções utópicas de Adorno é a analogia entre o agradável lar da criança que volta de férias com o tempo em que o mundo não estará mais sob a lei do trabalho, quando os deveres forem tão leves quanto a brincadeira:

À criança que regressa das férias, o lar parece novo, fresco, em festa. Mas aí nada mudou desde que ela o deixou. O simples esquecimento do dever, ao qual exorta cada móvel, cada janela, cada lâmpada, 
restaura a paz sabática, e por alguns minutos, na tabuada das salas, quartos e corredor, a gente está em casa de um modo tal que, a vida inteira, só o afirma a mentira. Não é de outro modo que, um dia, o mundo há de aparecer, sem mudanças quase, sob a luz incessante de seu dia feriado, quando não estiver mais sob a lei do trabalho e quando a quem torna à casa o dever for tão leve quanto o foi o jogo nas férias. (Adorno, 1993 [1951], p. 97).

Tal leveza também pode caracterizar a relação da humanidade com a natureza, como o exemplifica o amor das crianças pelos animais. Eles não fazem parte do mundo das trocas, são apenas eles mesmos, "por isso, as crianças os amam tanto e ficam tão felizes ao contemplálos" (Adorno, 1993 [1951], p. 200). A relação não coisificada com a natureza deriva da relação não coisificada entre os homens.

\section{Vida danificada, deperecimento da experiência e resistência}

Se a segurança e a experiência representam a vida, a insegurança e o deperecimento da experiência são as expressões dos danos. "Não há vida correta na falsa" (Adorno, 1993 [1951], p. 33). Essa famosa sentença adorniana encerra o aforismo "Asilo para desabrigados". Em uma analogia com os campos de concentração, o leitor se surpreende que o objeto do aforismo seja a sua própria casa. Com a nova arquitetura regredida à ergonomia e o consumo ascético de produtos como meras coisas, apagam-se os traços de comodidade e os sentimentos de estar abrigado. Sem o acolhimento do ambiente familiar, não há verdadeira independência. As novas moradias funcionam como tumbas para mortos vivos: "pertence à moral não sentirse em casa em sua própria casa" (Adorno, 1993 [1951], p. 32).

O aforismo "Não bater à porta" trata essencialmente do deperecimento da experiência, enfatizando a interdependência entre nossas relações com objetos e com seres humanos. Se em uma passagem anterior Adorno já afirmava que "um insensível desrespeito pelas coisas [...] se volta necessariamente também contra os homens" (Adorno, 1993 [1951], p. 33), agora escreve, na mesma página, que "a tecnificação torna, entrementes, precisos e rudes os gestos, e com isso os homens". Nos gestos, na mímica, podemos fazer um diagnóstico da patologia social. Nossa relação com as coisas pode ser descrita por uma manipulação, um manejo, que não possibilita relações elaboradas. "As portas dos carros e das geladeiras são para serem batidas, outras têm a tendência a fechar-se por si mesmas, incentivando naqueles que entram o mau costume de não olhar para trás, de ignorar o interior da casa que os acolhe" (Adorno, 1993 [1951], p. 33). Não olhar para trás e para o interior é uma bela figura de linguagem para a-historicidade e dificuldade em compreender a subjetividade. O método da microanálise 
fisiognômica é evidenciado quando Adorno afirma que "não se faz justiça ao novo tipo de homem, se não se tem consciência daquilo a que está incessantemente exposto pelas coisas do mundo a seu redor, até em suas mais secretas inervações" (Idem, p. 33). Um exemplo de hermenêutica materialista aplicada à atrofia da utopia e à canalização da agressividade pela violência intrínseca à técnica: "o que significa para o sujeito que não existam mais janelas que se abram como asas, mas somente vidraças de correr para serem bruscamente impelidas? [...] E qual o motorista que já não foi tentado pela potência do motor de seu veículo a atropelar a piolhada da rua, pedestres, crianças e ciclistas?” (Idem, p. 33).

Se nossos lares e nossas relações instrumentais com objetos formam uma parte do momento histórico em que vivemos, é preciso, além de olhar para trás, olhar para dentro. Qual a condição do Eu nesse contexto? Em seu asilo, o Eu desabrigado é descrito como o novissimum organum da reificação. Lembremos que na Dialética do Esclarecimento, no primeiro parágrafo do ensaio sobre o conceito de esclarecimento, Horkheimer e Adorno (1985, p. 19) fazem referência à obra Novum Organum de Francis Bacon como o símbolo do "programa de desencantamento do mundo" e de "substituição da imaginação pelo saber". O termo latino "organum" pode ser traduzido como "instrumento". Não foi por acaso o uso do termo "razão instrumental". O resultado do novo instrumento lógico da ciência nascente no século XVII foi o novíssimo instrumento de desencantamento da vida, o próprio Eu. Ele, agora, aparece como o instrumento da dominação social para a dominação das expressões internas, da espontaneidade. A conservação desse Eu é a perda do si mesmo. A organização interna desarticula a relação dos homens com seus próprios impulsos. O Eu não apenas está enredado na sociedade, mas também deve a ela sua existência no sentido mais literal. Todo seu conteúdo provém dela ou das relações com os objetos. Ele poderia ser mais rico de experiências quanto mais livre se desenvolvesse e refletisse a sociedade, mas, ao passo em que se enrijece, acaba por se estreitar e empobrecer.

Uma das defesas patológicas diante dessa condição do Eu é atribuir o sofrimento ou suas causas à natureza animalesca do ser humano. "A deformação não é nenhuma doença no homem, e sim uma doença da sociedade, que gera suas crias com aquela 'tara hereditária', que o biologismo projeta na natureza" (Adorno, 1993 [1951], p. 201). Como uma espécie de "Lombroso às avessas", podemos dizer que Adorno opõe a fisiognomia à frenologia, diagnosticando nos corpos traços de patologias e mutilações sociais. Contra o conceito de um instinto social irracional, afirma que "as tendências destrutivas das massas [...] não seriam 
tanto desejos de morte, quanto manifestações daquilo que já são. Eles assassinam para que a eles se iguale o que lhes parece vivo". (Adorno, 1993 [1951], p. 202).

Nossa rudeza é, ao mesmo tempo, expressão da violência e da resistência. Nossa composição orgânica, que decerto emergiu na dialética social, não diz respeito apenas às nossas capacidades técnicas, mas também ao que ganhou um aspecto de naturalidade e sucumbiu às contradições sociais. Trata-se do ingrediente agressivo que pode ter uma finalidade destrutiva, mas também compor a resistência e a transformação. A luta contra a opressão só é possível a partir dos impulsos agressivos. Lembremos a citação de Strindberg que faz Adorno (2000 [1968], p. 158) quando fala sobre educação contra a barbárie: “como eu poderia amar o bem, se não odiasse o mal”. A concentração, segundo ele, é uma ação derivada da energia utilizada para destruir objetos resistentes na infância, daí a expressão "trabalhando furiosamente" quando elevamos o nível de concentração. A possibilidade de sublimação dos impulsos agressivos (Adorno, 2000 [1968]), que ele encontra no próprio Freud, está na base de afirmações como "o talento talvez nada mais seja do que a fúria sublimada de um modo feliz" (Adorno, 1993 [1951], p. 95), ou que "cada obra de arte é um crime regateado" (Adorno, 1993 [1951], p. 96). Mesmo invenções mais práticas podem expressar algo da resistência, como chinelos e pantufas que "são concebidos de tal modo que se possa enfiar os pés neles sem o auxílio da mão. Eles são o monumento do ódio à postura de curvar-se" (Adorno, 1993 [1951], p. 95). A resistência e a luta contra a mentira do mundo carregam consigo a verdade da agressividade criativa.

\section{Considerações finais}

Finalizando a caminhada, e olhando para trás antes de fechar a porta, percebemos que nossa pergunta pela possibilidade do reconhecimento na vida danificada, no contexto do conflito geracional da teoria crítica, deve ser vista sob uma nova perspectiva. Os diversos elementos que construíram a história das leituras adornianas de Honneth acabaram por apontar para uma teoria do reconhecimento implícita no próprio Adorno. Nem sempre é evidente o tema da intersubjetividade na escrita fragmentária deste, mas a reconstrução de Honneth o sugere de forma plausível. Com isso parece concordar Jay Bernstein (2010, p. 33):

Em meus próprios escritos eu assumi tacitamente que ainda que Adorno não empregue diretamente a concepção hegeliana de reconhecimento da autoconsciência, entretanto, desde que a dialética senhor/escravo esteja por todos os lados em seus escritos, [...] sua teoria do sofrimento social deve depender indiretamente do modelo do reconhecimento. 
Ele elogia o esforço de Honneth em abordar o sofrimento social e tornar mais precisa sua abordagem como "não-reconhecimento" (misrecognition), mas o critica por uma abordagem formal, quase transcendental, na reconstrução da vida boa como reconhecimento. Para ele, Honneth "dá ao problema um maior nível de precisão, mas nada mais" (Bernstein, 2010, p. 45), pois ainda mantém a tentativa habermasiana de separar de forma asséptica e bem delimitada as razões comunicativa e instrumental.

Outro estudioso de Adorno que pensa de forma semelhante a aproximação com a teoria do reconhecimento é Philip Hogh (2016). Ele chega a mencionar os estudos de Tomasello como úteis para esclarecer o conceito de história natural em Adorno, mas vê em sua teoria da comunicação um desenvolvimento por demais harmonioso. Uma fértil linha de pesquisa poderia surgir desses problemas levantados por Bernstein e Hogh, considerando as importantes críticas ao conceito habermasiano de ação (Joas, 1996) e a uma leitura sociológica que, por enfatizar a dominação, tem negligenciado a cooperação - tema central de um trabalho mais recente de Tomasello (2014) que não foi considerado por Hogh.

Numa das poucas menções diretas a Honneth, Hogh menciona a controvérsia entre este e Joel Whitebook, cujo ponto central seria o abandono dos "habermasianos" da herança da negatividade deixada de Hobbes a Freud (Honneth, 2012b[2010]). Segundo Hogh (2016), o debate poderia se beneficiar com os escritos de Alfred Lorenzer, dos quais ele se vale para pensar a comunicação em Adorno. Vale a pena ressaltar, no entanto, que já na década de oitenta Honneth dirigiu críticas a Lorenzer, o que reaparece em texto bem mais recente para justificar a aproximação da teoria do reconhecimento com a psicanálise das relações objetais (Honneth, 2012a [2010]).

O maior desafio da teoria do reconhecimento, segundo Bernstein (2010), passa a ser a explicação de como uma teoria da intersubjetividade pode se conectar à experiência corporal do sofrimento. Honneth infere algumas antecipações de Adorno em relação à teoria das relações objetais, um campo de pesquisa que tem desenvolvido importantes pesquisas sobre intersubjetividade, comunicação corporal pré-verbal e sofrimento (Benjamin, 1988; Greenberg; Mitchell, 1983; Spitz, 2013; Winnicott, 1983). A crítica de Bernstein, se levamos em conta suas referências, não leva em consideração as discussões de Honneth em sua fase de aproximação com Adorno, na qual se dedica às questões do corpo, da mimese e dos gestos. 
O trabalho sobre a reificação (Honneth, 2008) apresenta textos de comentadores Judith Butler, Raymond Geuss e Jonathan Lear - que, de forma semelhante a Whitebook, criticam veementemente a "antropologia otimista" que o embasa ${ }^{8}$. Boa parte de seus questionamentos giram em torno de que o esquecimento do reconhecimento não poderia explicar a crueldade humana, tendo Honneth feito uma leitura seletiva da psicologia do desenvolvimento e da psicanálise. Apesar de algumas evidências de leitura imprecisa por parte de Butler, Honneth aceita as críticas como uma falha em sua exposição, que tratou muito pouco dos pressupostos necessários à compreensão de suas teses, expostos em obras mais antigas. Sua defesa é de que trata, nesse caso, de uma forma de reconhecimento anterior às que falava até então, sendo estas envolvidas em todo um complexo de instituições sociais. Entre as críticas à sua suposta antropologia otimista, que soam implicitamente como defesas da "antropologia pessimista" de tons hobbesianos, Honneth (2008) procura elucidar seus argumentos recorrendo a abordagens contextualistas da filosofia da linguagem, como as noções de "segunda natureza" de John McDowell ${ }^{9}$ ou da criação de fatos institucionais de John Searle.

Nossa intenção em chamar a atenção para nomes representativos da filosofia da linguagem, preocupados com as relações entre corpo, mente e instituições sociais, é destacar uma das potencialidades da teoria crítica atual. Além do método reconstrutivo do próprio Honneth, os esforços de sistematização da filosofia da comunicação e da linguagem de Adorno por Philip Hogh (2016) apontam para uma possível aproximação com a filosofia da linguagem mais recente. Hogh vê o frankfurtiano como um "pragmatista normativo" e "genealogista", que poderia fazer parte do grupo dos pós-formalistas como Wittgenstein, Davidson, McDowell, Derrida ou Merleau-Ponty. Também aponta para um possível diálogo entre a filosofia de Adorno e a de Putnam, como fez Honneth (2011 [1998]). Aqui se forma uma importante encruzilhada onde se encontram as teorias da comunicação e as das relações objetais, pois, para citar um exemplo invocado por Anthony Giddens (1991, p. 87),

\footnotetext{
a teoria das relações-objeto é informativa porque analisa como o indivíduo obtém um senso de coerência e como isto está ligado à renovação da confiança na "realidade" do mundo exterior. A meu ver, esta abordagem é (ou pode ser tornada) consoante com uma concepção wittgensteiniana do caráter de "dado" do mundo dos objetos e eventos, que pode ser "experimentado" apenas enquanto é vivido e que é intrinsecamente refratário a ser posto em palavras.
}

Se as questões entre reconhecimento, comunicação e linguagem parecem configurar um grande campo de pesquisa na atualidade da teoria crítica, em nosso "olhar para dentro" 
identificamos nossa contribuição como a construção de um possível diálogo entre psicologia, educação contra a barbárie e o reconhecimento dos direitos humanos. Temos dedicado nossos esforços a compreender as categorias psicológicas na teoria do reconhecimento de Axel Honneth e, mais recentemente, iniciamos um projeto para pesquisar como os contextos de valores se fazem presentes e são transformados criativamente nas brincadeiras infantis. Se já contávamos com as abordagens benjaminiana e honnethiana da eticidade e da "antropologia dialético/materialista" da infância (Benjamin, 2002), este trabalho contribuiu para considerar Adorno, para além de sua educação contra a barbárie, um pensador da ludicidade e da infância como normatividade. Os conceitos de mimese, experiência, segunda natureza, brincadeira e jogo formam uma constelação que pode iluminar as conjunções entre teóricos como Adorno, Benjamin, Mead e Winnicott. Uma reflexão crítica sobre o ato de educar para os direitos humanos pode aprender muito de uma genealogia da moral e da racionalidade que possa lidar com os signos da nova geração frankfurtiana sem se esquecer de sua ascendência.

\section{NOTAS}

\footnotetext{
${ }^{1}$ Professor Adjunto de Psicologia na Universidade Estadual de Feira de Santana (UEFS). Doutor em Psicologia Escolar e do Desenvolvimento Humano pela Universidade de São Paulo (Usp).

${ }^{2} \mathrm{O}$ uso do termo "retórica", apesar da conotação depreciativa que carrega na história da Filosofia, foi defendido pelo próprio Adorno enquanto forma adequada de expressão filosófica como "âmbito no qual a linguagem filosófica se reconhece enquanto tributária da dimensão estética" (DUARTE, 2016, p. 22). Ver também Adorno (2009 [1966a]; 2010 [1966b]).

3 Os temas da "constelação", de Benjamin, e dos "tipos ideais", de Weber, como método são abordados em Adorno (2009[1966a], pp. 140-4).

${ }^{4}$ Para uma exposição da antropologia expressivista, conferir Taylor, 2014, cap. I.

${ }^{5}$ Uma das epígrafes do texto de Honneth (2008) sobre reificação é a frase de Wittgenstein "o conhecimento está, no final, baseado no reconhecimento" (Knowledge is in the end based on aknowledgment).

${ }^{6}$ A expressão "forma primitiva do amor" traduz "Urform von Liebe". A tradução por "arquétipo do amor" pode nos ser útil, pois "archetype of love" é o termo que aparece em Honneth $(2008$, p. 44) quando se refere ao aforismo 99 de Adorno.

${ }^{7}$ Nesse contexto, seria interessante um estudo sobre a possibilidade de aproximação entre "valor de uso" e o "uso de um objeto" (Abram, 1996, pp. 34-37; Winnicott, 1975, cap. 6).

${ }^{8} \mathrm{Se}$, por um lado, temos um otimismo com ênfase na colaboração e, por outro, um pessimismo baseado na destrutividade, no sadismo e no masoquismo, parece-nos um caminho razoável, se queremos ir além da reprodução da controvérsia do tipo Hobbes/Rousseau, avançarmos em pesquisas sobre as bases antropológicas das duas vertentes. Para além das querelas centradas na negatividade em psicanálise, que parecem dar o tom das discussões, valeria a pena considerar a tradição antropológica expressivista, a sociologia e a filosofia da ação, o pragmatismo e a filosofia da linguagem.

${ }^{9}$ O próprio Honneth (2008) indica ao leitor seu estudo sobre McDowell (Honneth, 2011 [2001a]).
}

\section{REFERÊNCIAS BIBLIOGRÁFICAS}

ABRAM, J. The language of Winnicott: a dictionary of Winnicott's use of words. 2. ed. London: Karnac Books, 1996 
ADORNO, T.W. (1968). A educação contra a barbárie. In: ADORNO, T.W. Educação e emancipação. 2. ed. Rio de Janeiro: Paz e Terra, 2000. pp. 155-168.

(1966a). Dialética negativa. Rio de Janeiro: Jorge Zahar, 2009.

. (1966b). Lectures on negative dialectics. Cambridge: Polity Press, 2010.

Ática, 1993.

(1951). Minima moralia: reflexões a partir da vida danificada. 2. ed. São Paulo:

BENJAMIN, J. The bonds of love: psychoanalysis, feminism, and the problem of domination. New York: Pantheon Books, 1988.

BENJAMIN, W. Magia e técnica, arte e política: ensaios sobre literatura e história da cultura. 7. ed. São Paulo: Brasiliense, 1994. (Obras escolhidas, v. 1).

Ed. 34, 2002.

Reflexões sobre a criança, o brinquedo e a educação. São Paulo: Duas Cidades;

BERNSTEIN, J.M. Suffering injustice: misrecognition as moral injury in critical theory. In: RICHTER, G. (ed.). Language without soil: Adorno and late philosophical modernity. New York: Fordham University Press, 2010, pp. 30-51.

DUARTE, R. Expressão e constelação: elementos estéticos na Dialética Negativa. Cult, n. 215, ano 19, ago/2016. pp. 20-23.

FOSTER, R. Adorno: the recovery of experience. State University of New York Press, 2007.

GIDDENS, A. As consequências da modernidade. São Paulo: Editora Unesp, 1991.

GREENBERG, J.R.; MITCHELL, S.A. Object relations in psychoanalytical theory. Harvard University Press, 1983.

HOBSON, P. The craddle of thought. London: Pan MacMillan, 2002.

HOGH, P. Communication and expression: Adorno's philosophy of language. Lanham: Rowman \& Littlefield International, 2016.

HONNETH, A. (1988). Crítica del poder: fases en la reflexión de una Teoría Crítica de la sociedad. Madrid: A. Machado Libros, 2009.

(2000). Crítica reconstructiva de la sociedad con salvedad genealógica: sobre la idea de la "crítica" em la Escuela de Frankfurt. In: Patologías de la razón: historia y actualidad de la teoría crítica. Buenos Aires: Katz Editores, 2009. pp. 53-63.

(2001a). Entre la hermenéutica y el hegelianismo: John McDowell y el desafío del realismo moral. In: HONNETH, A. La sociedad del desprecio. Madrid: Trotta, 2011. pp. $205-233$

(2012a). Facets of the presocial self: rejoinder to Joel Whitebook. In: HONNETH, A. The I in we: studies in the theory of recognition. Cambridge: Polity Press, 2012. pp. 217-231. 
. (1986). Foucault and Adorno: two forms of the critique of modernity. In: HONNETH, A. The fragmented world of the social: essays in social and political philosophy. State University of New York Press, 1995. pp. 121-131.

(1979). From Adorno to Habermas: on the transformation of critical social theory. In: HONNETH, A. The fragmented world of the social: essays in social and political philosophy. State University of New York Press, 1995. pp. 92-120.

(2001b). Invisibilidad. Sobre la epistemología moral del "reconocimiento". In: HONNETH, A. La sociedad del desprecio. Madrid: Trotta, 2011. pp. 165-181.

(2006a). La apropriación de la liberdad: la concepción freudiana de la relación del indivíduo consigo mismo. In: Patologías de la razón: historia y actualidad de la teoría crítica. Buenos Aires: Katz Editores, 2009. pp. 139-158.

(2006b). La justicia en ejecución: la "Introducción" de Adorno a la Dialéctica Negativa. In: HONNETH, A. Patologías de la razón: historia y actualidad de la teoría crítica. Buenos Aires: Katz Editores, 2009. pp. 85-100.

(1992). Luta por reconhecimento: a gramática moral dos conflitos sociais. São Paulo: Editora 34, 2003.

(1981). Moral consciousness and class domination: some problems in the analysis of hidden morality. In: HONNETH, A. The fragmented world of the social: essays in social and political philosophy. State University of New York Press, 1995. pp. 105-119.

Reification: a new look to an old idea. Oxford: University Press, 2008.

(1998). Sobre la posibilidad de una crítica alumbrante. La Dialéctica de la Ilustración em el horizonte de los debates actuales sobre la crítica. In: HONNETH, A. La sociedad del desprecio. Madrid: Trotta, 2011. pp. 147-163.

(2001c). Sofrimento de indeterminação: uma reatualização da filosofia do direito de Hegel. São Paulo: Editora Singular, Esfera Pública, 2007.

(1989). Teoria crítica. In: GIDDENS, A.; TURNER, J. (Orgs.). Teoria social hoje. São Paulo: Editora Unesp, 1999. pp. 503-52.

- (2012b). The work of negativity: a recognition-theoretical revision of psychoanalysis. In: HONNETH, A. The $I$ in we: studies in the theory of recognition. Cambridge: Polity Press, 2012. pp. 193-200.

(2005). Una fisionomía de la forma de vida capitalista: bosquejo de la teoría social de Adorno. In: HONNETH, A. Patologías de la razón: historia y actualidad de la teoría crítica. Buenos Aires: Katz Editores, 2009. pp. 65-84.

HONNETH, A.; JOAS, H. (1980). Social action and human nature. Cambridge: University Press, 1988.

HORKHEIMER, M.; ADORNO, T.W. Dialética do esclarecimento: fragmentos filosóficos. Rio de Janeiro: Jorge Zahar, 1985.

JOAS, H. The creativity of action. Cambridge: Polity Press, 1996. 
MEAD, G.H. Mind, self, \& society: from the standpoint of a social behaviorist. The University of Chicago Press, 1967.

NOBRE, M.; REPA, L. (Orgs.). Habermas e a reconstrução: sobre a categoria central da teoria crítica habermasiana. Campinas, SP: Papirus, 2012.

SPITZ, R.A. O primeiro ano de vida. 4. ed. São Paulo: Martins Fontes, 2013.

STERN, D.N. The first relationship: infant and mother. With a new introduction. Harvard University Press, 2002.

TAYLOR, C. Hegel: sistema, método, estrutura. 2. ed. São Paulo: É Realizações, 2014.

TOMASELLO, M. A natural history of human thinking. Harvard University Press, 2014.

The cultural origins of human cognition. Harvard University Press, 1999.

WINNICOTT, D.W. O ambiente e os processos de maturação: estudos sobre a teoria do desenvolvimento emocional. Porto Alegre: Artmed, 1983.

O brincar e a realidade. Rio de Janeiro: Imago, 1975. 